\title{
HUBUNGAN KECERDASAN EMOSIONAL DAN MOTIVASI TERHADAP HASIL BELAJAR MATA KULIAH BAHASA INGGRIS DI JURUSAN KESEHATAN LINGKUNGAN POLITEKNIK KESEHATAN KEMENKES BANJARMASIN
}

\author{
Erminawati, Imam Santoso \\ Poltekkes Kemenkes Banjarmasin Jurusan Kesehatan Lingkungan Banjarbaru \\ Jl. H.Mistar Cokrokusumo No. 1A Kota Banjarbaru \\ e-mail : ermina wati85@ymail.com
}

\begin{abstract}
Relationship of Emotional Intelligence and Motivation on Learning Outcomes of English in the Environmental Health Departmen of Health Polytechnic Banjarmasin. The background of this research are 1) As a supporting subject of competencies English needs to get serious attention given the current health workers must have good communication skills in public. 2) English is still regarded as a difficult subject 3) There are still students who attend English language classes not because of her interest,. The purpose of the study was 1) to determine the effect of emotional intelligence on learning outcomes, 2) to determine the effect of motivation on learning outcomes, 3) to determine the effect of emotional intelligence and motivation together on learning outcomes. The design study was a descriptive study with cross sectional approach. The results showed the value of $p=0.788>\alpha=0.05$ then H0 was accepted; meaning that there was no significant positive relationship and emotional variables on learning outcomes. Similarly, for the variable of motivation on learning outcomes there was also a positive and significant relationship was indicated by a value of $p=0.929>\alpha=0.05$ then $\mathrm{HO}$ is accepted. Suggestion 1) that prior to learning both physically and mentally to be ready to accept what is presented by lecturer, 2) should be within the student must be no impetus to learn 3) teachers should understand what factors can affect the learning outcomes to be considered in the learning process.
\end{abstract}

Keywords : emotional intelligence; motivation

\begin{abstract}
Abstrak : Hubungan Kecerdasan Emosional dan Motivasi terhadap Hasil Belajar Mata Kuliah Bahasa Inggris di Jurusan Kesehatan Lingkungan Poltekkes Kemenkes Banjarmasin. Latar belakang dalam penelitian ini adalah 1) Sebagai Mata Kuliah pendukung kompetensi Bahasa Inggris perlu mendapatkan perhatian serius mengingat saat ini tenaga kesehatan harus memiliki kemampuan komunikasi yang baik di depan umum. 2) Bahasa Inggris masih dipandang sebagai mata kuliah yang sulit 3) Masih ada mahasiswa yang mengikuti perkuliahan Bahasa Inggris bukan karena minat dari dirinya,. Tujuan penelitian adalah 1) untuk mengetahui pengaruh kecerdasan emosional terhadap hasil belajar, 2) untuk mengetahui pengaruh motivasi terhadap hasil belajar, 3) untuk mengetahui pengaruh kecerdasan emosional dan motivasi secara bersama-sama terhadap hasil belajar. Desain penelitian yang digunakan adalah penelitian deskriptif dengan pendekatan cross sectional. Hasil menunjukkan nilai $\mathrm{p}=0,788>\alpha=0,05$ maka $\mathrm{H}_{0}$ diterima; artinya tidak terdapat hubungan yang positif dan signifikan variabel emosi terhadap hasil belajar. Begitu pula untuk variabel motivasi terhadap hasil belajar juga tidak terdapat hubungan yang positif dan signifikan yang ditunjukkan oleh nilai $\mathrm{p}=0,929>\alpha=0,05$ maka $\mathrm{H}_{0}$ diterima. Saran 1) agar sebelum belajar baik secara fisik maupun mental harus siap untuk menerima apa yang disampaikan oleh pengajar, 2) sebaiknya dalam diri mahasiswa harus ada dorongan untuk belajar 3) sebaiknya para pengajar memahami faktor apa saja yang dapat berpengaruh terhadap hasil belajar untuk dijadikan pertimbangan dalam proses belajar mengajar.
\end{abstract}

Keywords : kecerdasan emosional; motivasi

\section{PENDAHULUAN}

Pada era globalisasi sekarang ini, banyak sekali terjadi perkembangan ilmu pengetahuan, teknologi maupun perubah-

an pola pikir masyarakat. Tuntutan masyarakat terhadap kualitas dan profesionalisme pemberian pelayanan kese- 
hatan semakin meningkat. Tenaga kesehatan sebagai tenaga profesional juga dituntut untuk bertanggung jawab dalam memberikan pelayanan sesuai kompetensi dan kewenangan yang dimiliki secara mandiri maupun bekerja sama dengan anggota tim kesehatan lainnya.

Sebagai bahasa internasional dengan pemakai terbanyak di dunia bahasa Inggris menjadi bahasa asing yang terkenal yang sangat diperlukan oleh setiap insan saat berpindah lokasi ke luar wilayah Indonesia. Selama berada di luar negeri, bahasa Inggris merupakan bahasa penyatu dalam setiap negara.

Kemampuan berbahasa Inggris merupakan salah satu aspek penting yang harus dimiliki oleh mahasiswa. Dalam menghadapi persaingan global sekarang ini menitikberatkan pada kemampuan berbahasa asing terutama bahasa Inggris sangat penting karena kemampuan komunikasi merupakan kemampuan yang wajib dimiliki mahasiswa dalam menghadapi persaingan global. Kemampuan tersebut meliputi kemampuan berbicara, sosialisasi dengan orang lain, menjalin kerjasama, serta membangun jaringan dan lainnya.

Masalahnya adalah bagi sebagian besar orang bahasa Inggris merupakan momok yang membuat mereka merasa tertekan dan terbebani. Mendengar mata pelajaran bahasa Inggris yang terlintas di pikiran adalah sulit, sulit, dan sulit. Padahal sejak di bangku SMP (bahkan sekarang mulai di tingkat sekolah dasar) para siswa sudah diperkenalkan dengan pelajaran bahasa Inggris. Sampai ke tingkat pendidikan lanjutanpun mahasiswa akan bertemu dengan mata kuliah bahasa Inggris.

Hampir semua bidang ilmu dari berbagai jurusan selalu menyediakan bobot sks untuk mata kuliah bahasa Inggris. Hal ini dimaksudkan untuk menunjang kompetensi mahasiswa yang bersangkutan sesuai dengan bidang yang ditekuninya. Berbagai macam keterampilan berbahasa disampaikan pada mata pelajaran maupun mata kuliah bahasa Inggris seperti listening, speaking, reading, writing sampai dengan membekali mahasiswa untuk memahami serta untuk memanfaatkan sumber-sumber kepustakaan.

Dalam proses pembelajaran ada beberapa faktor yang memengaruhi hasil belajar yaitu faktor dari dalam diri seseorang maupun faktor dari luar atau faktor lingkungan seperti yang diungkapkan oleh Sudjana (2005:39). Faktor dari dalam seperti kemampuan yang dimiliki oleh peserta didik, motivasi belajar, minat dan perhatian, sikap dan kebiasaan belajar, faktor fisik dan psikis. Sedangkan faktor dari luar yang dapat mempengaruhi hasil belajar seperti kualitas pengajaran. Menurut Caroll (dalam Sudjana:2005: 40) hasil belajar peserta didik dipengaruhi oleh lima faktor, yaitu: bakat belajar, waktu yang tersedia untuk belajar, waktu yang diperlukan untuk menjelaskan pelajaran, kualitas pengajaran dan kemampuan individu.

Dalam proses pembelajaran, motivasi merupakan salah satu hal sangat diperlukan, sebab seseorang yang tidak mempunyai motivasi belajar, tidak akan mungkin melakukan aktifitas belajar dengan baik. Hal ini merupakan pertanda bahwa sesuatu yang akan dikerjakan itu tidak menyentuh kebutuhannya. Segala sesuatu yang menarik minat orang lain belum tentu menarik minat orang tertentu selama sesuatu itu tidak bersentuhan dengan kebutuhannya.

Adanya anggapan-anggapan bahwa bahasa Inggris itu sulit dan lemahnya motivasi seseorang dalam mempelajari bahasa Inggris mengakibatkan pencapaian prestasi belajar masih belum memuaskan. Berdasarkan paparan tersebut maka kami tertarik untuk meneliti permasalahan-permasalahan yang berhubungan dengan hasil belajar peserta didik dalam hal ini penelitian yang dilakukan memperhatikan dua hal terlebih dahulu yaitu pengaruh kecerdasan emosional dan motivasi terhadap hasil belajar mata kuliah bahasa Inggris di Jurusan Kesehatan Lingkungan Politeknik Kesehatan Kementerian Kesehatan Banjarmasin.

\section{BAHAN DAN CARA PENELITIAN}

Penelitian ini dilaksanakan di Jurusan Kesehatan Lingkungan Politeknik 
Kesehatan Kementerian Kesehatan RI Banjarmasin mulai bulan November s.d. Desember 2013. Desain penelitian yang digunakan adalah penelitian analitik dengan pendekatan Cross Sectional.

Instrumen yang digunakan dalam penelitian untuk mengumpulkan data dari responden adalah formulir/kuesioner berupa kisi-kisi berdasarkan indikator yang telah ditentukan dari masing-masing variabel. Populasi dalam penelitian ini adalah semua mahasiswa Jurusan Kesehatan Lingkungan yang mengambil mata kuliah Bahasa Inggris pada semester genap Tahun Ajaran 2011/2012. Sampel adalah total populasi yang berjumlah 35 orang.

Pengumpulan data primer dilakukan secara langsung dari mahasiswa sampling penelitian dengan cara mengisi formulir/kuesioner. Data Sekunder diperoleh dari daftar nilai mahasiswa yang diperoleh dari bagian akademik Jurusan Kesehatan ling-kungan.
Data yang diperoleh diolah menggunakan bantuan komputer program Statistik. Penyajian data dilakukan dalam bentuk tabel distribusi frekuensi, dan tabel silang antara variabel bebas dengan variabel terikat. Penyajian data dilakukan dalam bentuk naratif, tabel distribusi frekuensi dan tabel silang antara variabel independen dan dependen yang bertujuan untuk mengetahui hubungan kecerdasan emosional dan motivasi terhadap hasil belajar Mata Kuliah Bahasa Inggris di Jurusan Kesehatan Lingkungan Politeknik Kesehatan Kemenkes Banjarmasin. Analisis dalam penelitian ini menggunakan statistik Uji Korelasi.

\section{HASIL DAN PEMBAHASAN}

\section{Analisis Univariat}

Kecerdasan Emosi

Hasil pengolahan data dengan menggunakan program statistik diperoleh nilai mean, modus, media, standard deviasi, minimum dan maksimum seperti tabel berikut.

Tabel 1. Nilai Statistik Deskriptif Kecerdasan Emosi

\begin{tabular}{clcc}
\hline No. & & Statistik & Frekuensi \\
\hline 1. & Mean & 94.09 \\
2. & Median & 93.00 \\
3. & Modus & 95 \\
4. & Std. Deviasi & 7.920 \\
5. & Minimum & 81 \\
6. & Maksimum & 119 \\
\hline
\end{tabular}

Nilai emosional diambil dari daftar pertanyaan (kuesioner) yang diberikan pembobotan. Nilai tertinggi 5 (lima) dan nilai terendah 1 (satu). Setelah semua pertanyaan dijawab, selanjutnya dijumlahkan maka didapatkan nilai emosional untuk satu responden. Hasil pengolahan data me-nunjukkan nilai rata-rata (Mean) emosional mahasiswa 94,09 artinya mahasiswa mempunyai nilai yang tinggi saat mengikuti perkuliahan bahasa Inggris. Nilai emosional tertinggi 119 poin dan terendah 81 poin

\section{$\underline{\text { Motivasi }}$}

Hasil pengolahan data dengan menggunakan program statistik diperoleh nilai mean, modus, media, standard deviasi, minnimum dan maksimum seperti tabel 2.

Nilai motivasi seperti pada nilai emosional, diperoleh dengan cara yang sama, yaitu dengan menggunakan nilai pembobot-an. Nilai teringgi 5 (lima) dan nilai terendah 1 (satu). 
Tabel 2. Nilai Statistik Deskriptif Motivasi

\begin{tabular}{clcc}
\hline No. & & Statistik & Frekuensi \\
\hline 1. & Mean & 66.14 \\
2. & Median & 66.00 \\
3. & Modus & 67 \\
4. & Std. Deviasi & 4.095 \\
5. & Minimum & 59 \\
6. & Maksimum & 74 \\
\hline
\end{tabular}

Hasil pengolahan data menunjukkan nilai rata-rata (Mean) motivasi mahasiswa 66,14 yang artinya mahasiswa mempunyai nilai motivasi sedang saat mengikuti perkuliahan bahasa Inggris. Nilai motivasi tertinggi 74 poin dan nilai terendah 59 poin.

Tabel 3. Nilai Statistik Deskriptif Nilai Akhir

\section{Nilai Akhir}

Hasil pengolahan data menggunakan program statistik diperoleh nilai mean, modus, media, standard deviasi, minnimum dan maksimum seperti tabel berikut.

\begin{tabular}{clcc}
\hline No. & & Statistik & Frekuensi \\
\hline 1. & Mean & 75.26 \\
2. & Median & 75.00 \\
3. & Modus & 68 \\
4. & Std. Deviasi & 7.652 \\
5. & Minimum & 64 \\
6. & Maksimum & 91 \\
\hline
\end{tabular}

Apabila nilai akhir dalam bentuk numerikal ditransform menjad nilai huruf, maka akan diperoleh nilai seperti pada tabel 4. Nilai akhir diperoleh dari hasil rekapitulasi nilai akhir yang telah dikompilasi dengan penilaian aspek yang terdapat dalam nilai bahasa Inggris yaitu listening, speaking, reading, dan writing.
Hasil pengolahan data menunjukkan nilai rata-rata (Mean) yang diperoleh mahasiswa 75,26 poin artinya mahasiswa mempuyai nilai akhir pada kisaran tersebut atau kisaran nilai B. Nilai tertinggi mencapai 91 poin dan nilai terendah 64 poin.

Tabel 4. Distribusi frekuensi Nilai Akhir Mata Kuliah Bahasa Inggris

\begin{tabular}{cccc}
\hline No. & Nilai Akhir & Frekuensi & Percentasi (\%) \\
\hline 1. & $\mathrm{~A}$ & 10 & 28,6 \\
2. & $\mathrm{~B}$ & 20 & 57,1 \\
3. & $\mathrm{C}$ & 5 & 14,3 \\
\hline & Jumlah & 35 & 100 \\
\hline
\end{tabular}

\section{Analisis Bivariat}

Hubungan kecerdasan emosional terhadap hasil belajar.

Berdasarkan hasil perhitungan menggunakan program statistik pada uji normalitas Nilai Akhir diperoleh $\mathrm{p}=0,180$ dan nilai skor Kecerdasan Emosi pada $\mathrm{p}=0,081$; kedua variabel mempunyai nilai $p>\alpha(0,05)$ artinya kedua variabel tersebut "berdistribusi normal" yang merupakan salah satu persyaratan penggunaan uji korelasi Pearson. Selanjutnya dilakukan uji Korelasi diperoleh nilai $\mathrm{p}=$ $0,788>\alpha=0,05$ maka $\mathrm{H}_{0}$ diterima; artinya 
tidak ada hubungan variabel kecerdasan emosi terhadap variabel nilai akhir mata kuliah bahasa Inggris.

\section{Hubungan motivasi terhadap hasil} belajar

Setelah dilakukan Uji Normalitas diperoleh $\mathrm{p}=0,144$ (nilai skor motivasi), karena $p>\alpha(0,05)$ artinya variabel tersebut "berdistribusi normal" yang merupakan salah satu persyaratan penggunaan Uji Korelasi Pearson. Setelah dilakukan uji korelasi diperoleh nilai $p=0,929>\alpha=0,05$ maka $\mathrm{H}_{0}$ diterima; artinya tidak ada hubungan variabel motivasi terhadap variabel Nilai Akhir.

Seperti diungkapkan oleh Sudjana (2005:39) bahwa ada beberapa faktor yang dapat mempengaruhi hasil belajar seseorang yaitu faktor yang berasal dari dalam diri seseorang dan faktor dari luar atau faktor lingkungan.

Terhadap 35 orang mahasiswa yang menjadi responden dalam penelitian ini tidak terdapat pengaruh yang positif dan signifikan antara kecerdasan emosi dan hasil belajar. Terhadap pencapaian hasil belajar yang mereka peroleh mungkin disebabkan oleh beberapa faktor lainnya seperti faktor dari dalam diri mereka sendiri yang meliputi minat dan perhatian, sikap dan kebiasaan belajar, faktor fisik dan psikis. Adapun faktor dari luar atau faktor lingkungan meliputi kualitas pengajaran. Yang dimaksud dengan kualitas pengajaran adalah tinggi rendahnya atau efektif tidaknya proses belajar mengajar dalam mencapai tujuan pengajaran. Sedangkan menurut Caroll (dalam Sudjana;2005:40) hasil belajar siswa dipengaruhi oleh lima faktor, yaitu : bakat belajar, waktu yang tersedia untuk belajar, waktu yang diperlukan siswa untuk menjelaskan pelajaran, kualitas pengajaran dan kemampuan individu.

Berdasarkan hasil penelitian di atas memperlihatkan bahwa nilai bahasa Inggris dominan nilai B $(57,1 \%)$, dapat diinterpretasikan mahasiswa rata-rata sudah mempunyai kemampuan berbahasa Inggris walaupun masih perlu dikembangkan ke arah "berbahasa Inggris yang aktif". Apabila dilihat dari nilai kecerdasan emosi yang mempunyai nilai rata-rata (mean) 94,09 point dengan nilai tengah (modus) 93 point, artinya mahasiswa sudah mempunyai kecerdasan emosi yang "tinggi", walaupun tidak diikuti oleh tingginya tingkat motivasi yang mempunyai nilai rata-rata (mean) 66,14 point dengan nilai tengah (modus) 66 point. Sehingga nilai akhir yang diperoleh pada mean 75,26 point; dalam aturan akademik akan dihargai setingkat nilai $B$.

Secara statistik dengan Uji Korelasi Pearson hubungan kecerdasan emosi terhadap nilai akhir mata kuliah bahasa Inggris diperoleh nilai $\mathrm{p}>\alpha$, hipotesis Ho diterima artinya tidak ada hubungan yang signifikan. Demikian pula hubungan motivasi terhadap nilai akhir mata kuliah bahasa Inggris diperoleh nilai $\mathrm{p}>\alpha$, hipotesis Ho diterima artinya tidak ada hubungan yang signifikan.

\section{KESIMPULAN DAN SARAN Kesimpulan}

Dari penelitian yang telah dilakukan terhadap 35 responden dapat disimpulkan bahwa :

1. Dari hasil pengolahan data dengan nilai rata-rata emosional mahasiswa 94,09 berarti bahwa kecerdasan emosi mahasiswa pada saat mengikuti perkuliahan bahasa Inggris sangat bagus

2. Dari hasil pengolahan data motivasi diperoleh nilai rata-rata 66,14 menunjukkan bahwa pada saat mengikuti perkuliahan bahasa Inggris mahasiswa memiliki motivasi yang sedang.

3. Dari penelitian yang telah dilakukan diketahui bahwa tidak ada hubungan yang signifikan kecerdasan emosi dan motivasi terhadap hasil belajar

\section{$\underline{\text { Saran }}$}

1. Agar dapat berhasil dalam proses belajar, sebaiknya mahasiswa sebelum belajar baik secara fisik maupun mental harus siap untuk menerima apa yang disampaikan oleh pengajar/ dosen.

2. Untuk mencapai sebuah keberhasilan, sebaiknya dalam diri mahasiswa harus ada dorongan untuk belajar, sehingga dalam mengikuti proses belajar (perkuliahan) mahasiswa tidak merasa terbebani. 
3. Dalam melaksanakan proses belajar mengajar, sebaiknya para pengajar/ dosen memahami faktor apa saja yang dapat berpengaruh terhadap hasil belajar peserta didik dan hendaknya memberikan perhatian terhadap faktor-faktor tersebut agar dapat menunjang hasil belajar mahasiswa.

\section{DAFTAR PUSTAKA}

1. Hajaroh, Mami, Kecerdasan Emosional dan Pengaruhnya terhadap Pendidikan Seseorang.

2. Goleman, Daniel. (2006) Kecerdasan Emosional: Mengapa EI lebih penting dari IQ. Gramedia Pustaka Utama, Jakarta
3. Mitchell, T. R. Research in Organizational Behavior. Greenwich, CT:JAI Press, 1997.

4. Robbins, Stephen P.; Judge, Timothy A. (2008). Perilaku Organisasi Buku 1, Salemba Empat, Jakarta

5. Maslow. (Inggris)A. Motivation and Personality. Harper \& Row, 1954, New York

6. Robbins, Stephen P.; Judge, Timothy A. (2008). Perilaku Organisasi, Salemba Empat, Jakarta

7. Sudjana, Nana, 2005. Dasar-Dasar Proses Belajar Mengajar. Band Algensindoung: Sinar Baru. 